Article

\title{
Talking about sex in Malawi: toward a better understanding of interpersonal communication for HIV prevention
}

\author{
Rupali J. Limaye, Rajiv N. Rimal, Glory Mkandawire, Peter Roberts, William Dothi, \\ Jane Brown \\ Johns Hopkins Bloomberg School of Public Health, Baltimore, USA
}

Significance for public health

Our study points to a lack of self-efficacy to talk about issues of sexual health and relationships among parents and children, partners, and peers. This comes from a lack of confidence and skill in how to talk about sex and relationships. The responsibility for public health practitioners is to help individuals become more confident about and capable of talking about sexuality in a more positive and productive and less stigmatizing way. Interventions should help parents better understand the concerns and aspirations of children and vice-versa; to model, between partners, positive gender norms and deeper discussion around shared responsibilities. Interventions should use media, at the national and local level, fictional and non-fictional, to exponentially expand the dialogue around the complexities of living in a time of AIDS; to scale up local community dialogue through small group discussions, and advocacy among leaders. Silence fosters taboos; dialogue and public discourse breaks them.

\section{Abstract}

The generalised AIDS epidemic in Malawi presents many challenges. As communication and advice from parents, peers, and partners are important factors in influencing sexual behaviour, understanding communication may provide insights into behaviour change programming. This mixed-method study used a household survey $(n=1812)$ and 15 focus group discussions from the southern districts of Malawi to explore communication about sex and sexuality. Quantitative study findings point to the idea that self-efficacy, perceived benefits, and injunctive norms about talking about condom use are important factors influencing intentions to discuss condom use with partners. Qualitative study findings found that communication regarding sex between parents and children, partners, and peers was not common, and when there was communication, messages about sex focused on negative consequences of sexual activity. In Malawi, there is a need to increase efficacy in talking about sex and protective sexual behaviours, including condom use. Interventions should include components to increase communication skills, shift norms about sexual communication, and provide alternative mechanisms for individuals to gather pertinent information regarding their sexual behaviour.

\section{Introduction}

With an estimated prevalence of $11 \%$ among those aged $15-49,{ }^{1}$ the AIDS epidemic in Malawi is a formidable problem. Transmission is driven by heterosexual sexual activity, as $90 \%$ of infections stem from heterosexual transmission. ${ }^{2}$

Due to the high rates of sexual transmission, changing sexual behaviour is crucial to averting new infections. By the age of $18,60 \%$ of girls and $53 \%$ of boys in Malawi will have had sex. ${ }^{1}$ Rates of condom use are generally low among Malawians: among adults aged 15$49,3 \%$ of women reported currently using either male or female condoms and $13 \%$ of men reported using either a male or female condom the last time they had sex. ${ }^{1}$ There are also low rates of condom use in higher-risk sexual encounters, such as non-marital sex, sex with a non-cohabitating partner, and transactional sex. ${ }^{1}$

To reduce HIV exposure, Malawians must be knowledgeable about the types of risks associated with different types of sexual behaviour. Yet in Malawi, appropriate sex education does not appear to be widely available and sex education in schools does not provide young people with adequate information about sexual health issues. ${ }^{3}$ Outside of schools, Malawian elders were traditionally tasked with instructing children about sexual health norms and information about protection against the risks involved, but this practice is diminishing. ${ }^{3}$ As a result, many Malawians obtain sexual health information, including information on HIV/AIDS, through interpersonal communication with members of their communities, ${ }^{4,5}$ and sexual health information obtained from these discussions may not be accurate. ${ }^{3}$

Previous studies have identified families, peers, schools, workplaces, communities, cultural systems and media as sources of information on HIV/AIDS. ${ }^{4,5}$ Parents and peers have also been identified as important socialising agents for sexual behaviour within, as well as outside, Malawi. ${ }^{6,7}$

Although there is overwhelming evidence for the need to involve parents as part of a comprehensive strategy for improving young people's health, ${ }^{8}$ including communication regarding sexual health, there are conflicting reports as to whether parents in sub-Saharan Africa communicate with their children about sexual health and the effect such communication has on young people's sexual behaviour. Parent-child communication has been shown to be associated with a range of behaviour patterns to protect sexual health, including delayed first sex,${ }^{9}$ fewer incidences of unsafe sex in general, ${ }^{10}$ fewer sexual partners and increased use of condoms, ${ }^{11}$ and other contraceptives. ${ }^{12,13}$ Others have not found any association between parentchild communication and sexual risk behaviours. ${ }^{14}$ These differences may be attributed to the content, timing and frequency of communication, as well as parent-child relationship characteristics. Studies show, for example, that the process, content, and communicator characteristics play a role in influencing young people's attitudes and sexual practices. ${ }^{15}$ Because young people particularly value openness in discussing sex in preference to judgmental lectures, ${ }^{16}$ those designed simply to impart advice may be less effective.

Besides parental communication, partner communication is an important variable in affecting sexual behaviour. Studies conducted outside Malawi have found that safer sexual behaviour requires 
interpersonal communication and cooperation between partners. In particular, if a female wishes to have safer sex through the use of a condom, she must communicate this request to her partner. ${ }^{17}$ Communication and negotiation for safer sex play a major role in HIV prevention because condom use is a primary method for preventing sexual transmission of HIV, ${ }^{18}$ and the ability to discuss sexual issues with a partner is a key factor in HIV prevention. ${ }^{19}$

Previous research has also shown that peer influences, including influences on sexual behaviour, increase during adolescence and continue into adulthood..$^{20,21}$ As conversations with peers are typically friendlier than conversations with parents or other relatives, peerto-peer conversations may be better suited to facilitate discussions related to sex. ${ }^{20}$

In this study, we adopted a mixed-method approach to understand how Malawians view interpersonal communication about sex and sexuality. Two theoretical perspectives, social cognitive theory ${ }^{22}$ and the theory of normative social behaviour, ${ }^{23}$ informed our research focus on self-efficacy and normative beliefs as important determinants of discussion about sex in Malawi. We first analysed survey data to determine what factors contribute to intentions to talk about condom use. In particular, we focused on the role of self-efficacy to engage in discussions, perceived benefits of doing so, and normative beliefs about the extent to which others engage in discussions about condom use. In the second part, we adopted a qualitative approach in order to further explore the role of discussion between partners, between parents and children, and among peers. For clarity, we have designated the quantitative analysis as Study 1 and the qualitative analysis as Study 2.

\section{The BRIDGE 2 project}

Although the estimated HIV prevalence in Malawi is 11\%, prevalence in the southern region, where more than half of the country's population lives, is $14.5 \% .^{2}$ To strengthen prevention efforts in Malawi, the Johns Hopkins Bloomberg School of Public Health Center for Communication Programs implements the BRIDGE 2 project in 11 districts in the southern region. BRIDGE 2 is a 5-year intervention aimed at changing behaviour, and its purpose is to scale up and expand HIV/AIDS prevention activities in Malawi by removing barriers to individual action and confronting specific drivers of behaviour at the normative/society level. Data for both studies come from the baseline research conducted before the start of BRIDGE 2. Ethical approval was obtained from institutional review boards in Malawi (the National Research Council and the Health Services Research Committee in the Ministry of Health and Population Services) and the United States (Johns Hopkins Bloomberg School of Public Health Institutional Review Board).

\section{Study \#1}

Previous work has focused on the role played by interpersonal communication in HIV/AIDS-related outcome ${ }^{24-26}$ but, to our knowledge, factors that may influence communication about sex itself have not been studied in Malawi. The primary goal of the quantitative assessment was to determine the correlates of people's intentions to talk about sex and sexuality. In order to make predictions about factors likely to be associated with discussion intentions, we relied on two theoretical perspectives. First, based on social cognitive theory, ${ }^{22}$ we hypothesised that self-efficacy to discuss sex and sexuality would be associated with intentions to engage in discussion about the topic. Second, because discussions about sex and sexuality are often normatively defined as being appropriate or inappropriate according to the particular context and nature of the interpersonal relationship, ${ }^{27-}$ ${ }^{29}$ we relied on the theory of normative social behaviour ${ }^{23}$ to make predictions about factors associated with discussion intentions. In particular, the theory of normative social behaviour (TNSB) posits that descriptive norms (perceptions about the prevalence of a type of behaviour) and injunctive norms (pressures one feels to conform) affect our behaviour or behavioural intentions. Furthermore, the relationship between descriptive norms and behaviours or behavioural intentions is moderated by injunctive norms and outcome expectations. The underlying idea is that people are affected by descriptive norms particularly if they perceive that injunctive norms to conform are also strong or that enacting the behaviour confers many benefits.

\section{Design and Methods}

Malawi is divided into districts below which sit the traditional authorities (TAs) that are administrative units similar to counties in many countries. Below the TAs are villages. We designated each district's TAs as either treatment or control according to whether future BRIDGE 2 interventions were planned there. Sampling for the data collection was carried out by randomly choosing villages in each TA and then randomly choosing households in proportion to population size from the selected village. One eligible adult was chosen at random from the selected household. Members of a Malawian research firm, who were first trained in human subjects' ethics and interview techniques, conducted oral interviews in Chichewa. The survey instrument was translated into Chichewa, pilot tested, modified, and translated back into English.

\section{Measurements}

Demographic indicators comprised gender, age, education (years of formal schooling), number of children, and income. Income represented the total score of the number of household items possessed by the respondent from a list that included electricity in the home, telephone, and running water. Because of the long tail in the distribution of the number of children, this variable was recoded in the regression equations; those with more than three children were coded as 4 .

Self-efficacy in talking to a partner was evaluated according to the average response to three questions $(\alpha=0.81)$ about participants' confidence in their ability to talk to their sexual partner about condom use. Responses were framed in 5-point Likert-type scales, ranging from 1 (strongly disagree) to 5 (strongly agree). Questions included: If your sexual partner does not talk about condoms, you can bring up the topic with him or her; You can talk about using a condom with the person with whom you're going to have sex; and You can negotiate condom use with your partner.

Perceived benefit of talking about condom use was measured as participants' agreement that talking with a sexual partner about using a condom will help you and your partner reach an agreement about using it.

Descriptive norms about discussion about condom use were measured as the average response to two questions $(\mathrm{r}=0.64)$ both of which were scored on 5 -point scales $(1=$ none and $5=$ almost everyone $)$ : About how many of the people in your community talk to their sexual partner about using condoms? and About how many other (males/females) in your community talk to their partners about using a condom? For this last question, males were asked about males and females were asked about females.

Injunctive norms about discussion about condom use were measured as participants' estimate about how many people in their community would approve or disapprove of them talking to their sexual partner about using condoms; responses were scored on a 5-point scale, ranging from 1 (almost all would disapprove) to 5 (almost all 
would approve).

Intention to talk about condom use was measured as participants' level of agreement with the statement that they intend to talk about the use of a condom the next time they have sex. Responses were coded on a 5-point scale, ranging from 1 (strongly disagree) to 5 (strongly agree).

\section{Results}

Table 1 shows the demographic characteristics of the study sample for males and for females, and statistical tests of differences between them. Overall, males in the sample were older, better educated, and wealthier than females. Males also had fewer children than females. There was no difference between males and females in the percentage of those who lived alone or in terms of the percentage of Christians in the sample. Compared to females, males perceived greater efficacy in talking about condom use and they believed that more of their peers talked about condom use with their partners. There was no difference in perceptions about the benefits of or injunctive norms pertaining to talking about condom use between males and females. There was also no difference in their intentions to talk about condom use.

Table 2 shows the results of the multiple linear regression equations in which intentions to talk to a sexual partner about using con- doms was used as the dependent variable. Zero-order Pearson's correlations are also shown. Many relationships shown in the first two columns in Table 2 are similar, but a few exceptions are noteworthy. For example, the relationship between education and intention to discuss condom use was significant in the zero-order correlation but it is significantly reduced in the regression model when the influence of other variables is taken into account. Similarly, the number of children in the home was negatively associated with intention, while household possession was positively associated, but only in the bivariate model. The association between descriptive norms and intention was also only significant in the bivariate and not the multivariate model.

Efficacy in talking about condom use and perceived benefits of condom use were significantly associated with intention to talk about condom use. Injunctive norms were also significantly associated with intention to discuss condom use.

The interaction between perceived benefits and descriptive norms was significant. None of the other interactions between descriptive norms on the one hand and injunctive norms and self-efficacy on the other hand was significant.

In order to illustrate the nature of the interaction, we followed the Aiken and $W^{3}{ }^{30}$ guidelines and plotted the relationship between descriptive norms and discussion intentions along three values of the moderator (perceived benefits): at one standard deviation above the mean, at the mean, and at one standard deviation below the mean. The pattern of the interaction is shown in Figure 1.

Table 1. Study subjects' characteristics $(n=1812)$.

\begin{tabular}{|c|c|c|c|}
\hline Variable & $\begin{array}{c}\text { Male }(\mathrm{n}=889) \\
\mathrm{M}(\mathrm{SD}) \%\end{array}$ & $\begin{array}{c}\text { Female }(\mathrm{n}=923) \\
\text { M (SD) } \%\end{array}$ & $t$-test or $\chi^{2}$ \\
\hline Age (years) & $28.45(11.5)$ & $26.99(10.4)$ & $2.83^{* *}$ \\
\hline Education (years) & $6.96(3.28)$ & $5.62(3.39)$ & $8.57^{* * *}$ \\
\hline N. of children & $1.85(2.28)$ & $2.26(2.09)$ & $3.91^{* * *}$ \\
\hline Household possessions $(0-1)$ & $0.32(0.15)$ & $0.28(0.15)$ & $5.31^{* * *}$ \\
\hline Live alone & 38.1 & 35.1 & 1.93 \\
\hline Christian & 84.0 & 85.8 & 1.12 \\
\hline Efficacy in talking to partner (1-5) & $4.68(0.85)$ & $4.44(1.12)$ & $5.11^{* * *}$ \\
\hline Perceived benefits in talking (1-5) & $4.79(0.82)$ & $4.78(0.81)$ & 0.28 \\
\hline Descriptive norms about talking (1-5) & $2.50(0.86)$ & $2.42(0.85)$ & $2.08^{*}$ \\
\hline Injunctive norms about talking (1-5) & $3.27(1.01)$ & $3.21(1.01)$ & 1.37 \\
\hline Intention to talk (1-5) & $4.54(1.21)$ & $4.51(1.22)$ & 0.63 \\
\hline
\end{tabular}

$t$-test and 2 test compare differences between males and females in the sample. ${ }^{*} \mathrm{P}<0.05 ; * * \mathrm{P}<0.01 ;{ }^{* * *} \mathrm{P}<0.001$

Table 2. Predictors of intention to talk about condom use with sexual partner from regression equations.

\begin{tabular}{|c|c|c|c|c|}
\hline Predictor & $r^{\circ}$ & $\beta^{\#}$ & (SE) & $\mathrm{R}^{2 \$}$ \\
\hline Female & -0.02 & 0.02 & $(0.05)$ & \\
\hline Age & $-0.21^{* * *}$ & $-0.16^{* * *}$ & $(0.00)$ & \\
\hline Education & $0.12^{* * *}$ & 0.02 & $(0.01)$ & \\
\hline N. of children & $-0.14^{* * *}$ & 0.02 & $(0.02)$ & \\
\hline Household possession & $0.08 * *$ & 0.01 & $(0.17)$ & \\
\hline Efficacy in talking to partner & $0.44^{* * *}$ & $0.33^{* * *}$ & $(0.03)$ & \\
\hline Perceived benefits of talking & $0.35^{* * *}$ & $0.24^{* * *}$ & $(0.03)$ & \\
\hline Descriptive norms about talking & $0.10^{* * *}$ & 0.01 & $(0.03)$ & \\
\hline Injunctive norms about talking & $0.17^{* * *}$ & $0.09 * * *$ & $(0.03)$ & \\
\hline Perceived benefits $\mathrm{x}$ descriptive norms & -0.01 & $0.06^{* *}$ & $(0.03)$ & $0.278^{* * *}$ \\
\hline
\end{tabular}

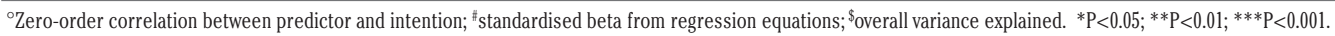


Figure 1 shows a strong main-effect of perceived benefits as illustrated by the placement of the three lines corresponding to low, medium, and high values. Those who believed that talking about condom use conferred many benefits were more likely to have stronger intentions to talk about the topic with their sexual partners. The interaction pattern shows that if perceived benefits were low or if they were of medium level then descriptive norms and intentions were not associated with each other (beta values were 0.01 and -0.05 , respectively). The opposite pattern was found when perceived benefits were high: higher descriptive norms were associated with greater intentions to talk about condom use $(\beta=0.07, \mathrm{P}<0.05)$.

\section{Study \#2}

Given Study 1 findings on normative influences on interpersonal discussions on condom use, the primary goal of the qualitative assessment in Study 2 was to explore what kinds of information about sex and sexuality, and HIV/AIDS-related behaviours in particular, Malawians discuss through interpersonal communication. Besides evidence from previous studies that Malawians rely on information about sex and sexuality from their personal networks, ${ }^{4,5}$ interpersonal communication has been found to be an influential factor in sexual behaviour. ${ }^{24} \mathrm{We}$ relied on uncertainty reduction theory ${ }^{31}$ to guide our inquiry regarding the methods by which Malawians seek information. The theory states that when individuals experience uncertainty, they are motivated or driven to seek information to reduce it. ${ }^{32}$ Uncertainty can be reduced by gathering information that is perceived to be adequate to the individual to be able to make a decision or come to an opinion about the topic of interest. ${ }^{33}$ The need to reduce uncertainty pushes individuals toward cognitive clarity and, as a result, individuals demand clear formulations from those around them. ${ }^{34}$ Specific to Malawi, as sex education within schools is inadequate and the role of Malawian elders as providers of sexual health information is decreasing, ${ }^{3}$ it is likely that Malawians are turning to their personal networks to gather information and to reduce uncertainty relating to sexual behaviour.

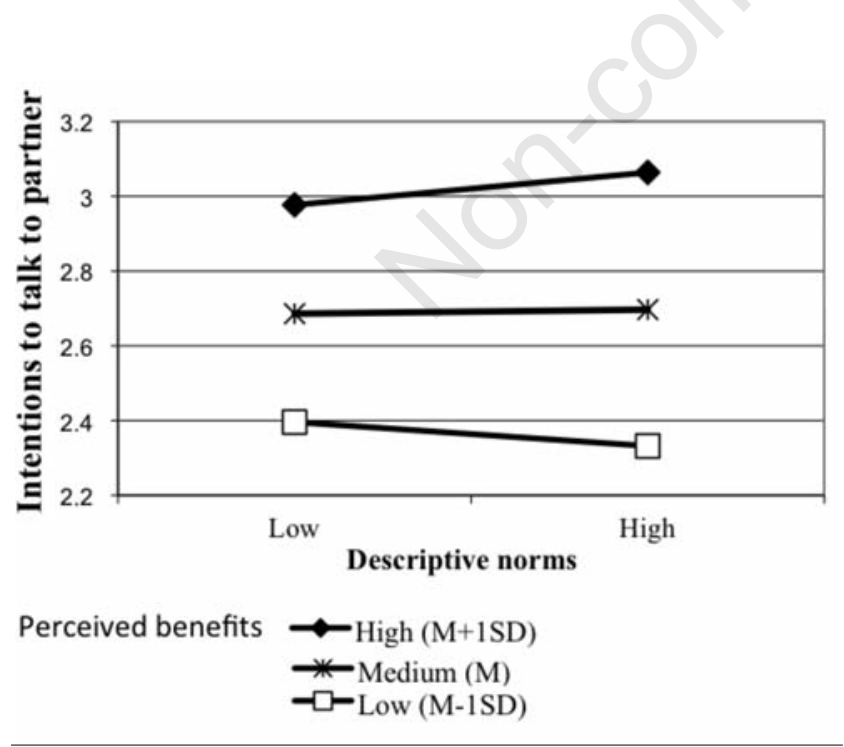

Figure 1. Relationship between descriptive norms and intentions to talk about condom use with partner at three levels of perceived benefits.

\section{Design and Methods}

\section{Study sample and recruitment}

This study was conducted in three districts in southern Malawi: Blantyre, Chiradzulu and Neno. A total of 15 focus group discussions (FGDs) were conducted across districts using a stratified purposeful sampling approach ${ }^{35}$ and both urban and rural areas were sampled from each district. The study divided groups into the following categories to facilitate the most comfortable group dynamics and open discussion: men aged 15-24 years, men aged 25-49, women aged 15-24, women aged $25-49$, and mixed genders aged over 50 . To alleviate any possible sexual tension, we stratified the sexually active age group (1549 years) according to gender; however, we did not stratify the other age groups. In total, 150 people took part in the study, approximately half females and half males, with 10 participants in each focus group. To increase the chances of eliciting honest responses, we did not ask anyone to give their name and we asked group members what others in their community did, rather than asking community members about their own behaviour. We also only employed FGD facilitators who were not from any of the communities where the FGDs took place.

For recruitment purposes, the study staff obtained a list of active community-based organisations in the study areas. Community-based organisations, specifically organisations involved in HIV awareness, and women's and human rights nominated participants for the FGDs. The study supervisor visited all nominated participants and explained the purpose of the study. Participants were screened to ensure they met age and gender eligibility criteria. Eligible individuals were then invited by the study supervisor to join a focus group. All participants gave their informed consent to the study.

\section{Data collection}

The pre-tested guides included open-ended questions addressing a variety of topics: pressing community problems, efficacy in solving community problems, the various forms of sexual relationships common in the study population, and community definitions of sexual relationships. Focus group discussions lasted 60-90 minutes and were conducted in the Chichewa language. Discussions were tape recorded and transcribed verbatim. Short field notes were taken. Recordings were translated from Chichewa into English. Project staff members fluent in both languages reviewed translations for accuracy.

\section{Data analysis}

The first author (RJL) analysed English-language transcripts independently. Data were analysed thematically in a multi-step process using the constant comparative method that is central to grounded theory ${ }^{36}$ First, several transcripts were read for content comprehension, and two transcripts were chosen for open coding by the analyst. During the open coding process, memos were written to help develop themes that were emerging from the data. These themes were then synthesised into a code list based upon recurring concepts. The resulting code list was then used to code the next two transcripts; this step was conducted to assess the similarity as well as the differences among the transcripts and to compare data across the groups. The list was then used to code the remaining transcripts. As new themes emerged, the code list was again refined and previously coded interviews were recoded as necessary. Analytic memos were written throughout the coding process to reflect on themes within and across interviews for cross-coding and other points of interest. Atlas-ti@ software, version 6.0 was used to manage and code data. 


\section{Results}

Six main themes, each related to a communication barrier, were identified. As themes varied across confidant type (parent/elder-tochild, partner-to-partner, or peer-to-peer), analysis was conducted by confidant type within each barrier. Lack of openness, a focus on the negative consequences of sex, and undefined communication roles were identified as main issues at the parent-child level. At the partner level, implied unfaithfulness and fear of relationship termination emerged as dominant issues. At the peer level, fear of rumour and gossip was a major barrier to communication about sexual issues.

The main form of communication was between parent or elders and children. Within this discussion, parents/elders usually initiated the communication and the young people characterised communication and advice about sex from their elders as warnings, often presented in the form of threats. In communication between partners, partners were fearful of discussing sexual issues because of implied cheating, and at the peer level, subjects were worried that discussions with their peers would be passed onto others in the community as gossip.

\section{Lack of openness}

Parents believed that they attempted to discuss sexual health issues with their children, but they felt constrained by norms regarding sexual communication. Most of the parents perceived talking about sex with one's children as shameful and immoral. Parents believed that speaking to children about sex encouraged sexual activity:

No, we can't (talk to children about sex) because the children can go on to try the thing... They will go try it if you tell them. (Female, 25-49 years age group).

Parents often spoke about how Malawian customs restricted parentchild communication about sex. Taboos relating to parental advice about sex, as well as the perception that the Malawian way of life did not allow for discussions about sex, was heavily reflected in parental ease in talking to young people. A male parent suggested that speaking to a child about sex could never happen:

We have never come across a parent telling (a child about sex)... because it is impossible to discuss such things with your child ... our ignorance is the custom. (Male, 25-49 years age group).

A major constraint identified by study participants was the environment. Parents believed that open dialogue was not the norm in their communities. Parents felt that their community culture was not conducive to discussing issues about sex or other sensitive topics:

The openness is not yet established because things (reach) us late here... even (HIV) testing is just getting established. So it will take some time for the openness to be established. (Male, 25-49 years age group).

Similar to the parent perspective, children also felt that the open environment necessary to discuss sexual matters had not yet been established in Malawi. Many children in our study wanted to speak to their parents about sexual health issues but were hesitant to ask, as seen in this statement by a young teenage girl:

...We have the desire to ask (about sex), but we are shy. (Female, 1524 years age group).

Young adult males were embarrassed about speaking to their parents about possible relationships and, therefore, sexual activity. As a result, many young people said they hid their relationships from their parents:

No, to me I have never talked with my parents about sex... we hide our lovers... we (hide them) so that they should not know...(about our) issues of sex... (Male, 15-24 years age group).

\section{Undefined communication roles}

Another barrier parents faced was confusion about who was supposed to talk to children about sexual health issues. Male parents and grandparents believed that it was not their role to discuss sexual issues with children:

Men are not allowed to advise children ... we men do not have the privilege of advising children. (Male, 25-49 years age group).

Males believed it was improper for fathers to be close to their daughters and, therefore, inappropriate to talk about personal issues, such as sex. Although fathers were not close to their daughters, they expected their wives to be and, therefore, assumed that their wives spoke to their daughters. Men believed that speaking to their daughters about sexual health issues implied a sexual relationship, as illustrated by this quote:

Respect stipulates that a man cannot talk about such strong matters to a daughter... especially sex... it is assumed that if you do (talk about sex) then you are sleeping with her... here we are not supposed to be too bold to our daughters. (Male, 25-49 years age group).

Due to the difficulty in communicating with their children, many parents believed that children should not learn about sex through either parent but rather through communication programmes. This male parent believed that his role was to only communicate fear about AIDS:

(Communication about sex) is not much in our area... let them hear from (the) radio. They should hear (about sex itself) on the radio... we can just talk (to them so that they know and should be) afraid that there is AIDS. (Male, 25-49 years age group).

There appeared to be a lack of health advisors in the communities involved in the study. Adults expressed concern that there was no individual in charge of communicating issues regarding sex to their children:

In rural areas like these we just hear (about sex and HIV/AIDS) from the radio...like people are learning ways in which they can prevent AIDS ...But in rural areas like this one, there are not any advisers who talk about AIDS. (Male, 25-49 years age group).

Young people also suggested that they receive little information on HIV/AIDS from others in their communities. A young girl said that learning about HIV/AIDS was rare in her community:

So, it's like... we learn for example (about sex) if we are in a (focus) group like this one; (we learn that getting an HIV) blood test is good, sexual intercourse is not good and can lead to troubles...parents are shy to (talk to) their children (about sex). (Female, 15-24 years age group).

\section{Implied unfaithfulness}

In the context of partner-to-partner communication, males were fearful of discussing sex, including protective behaviour, with their female partners because these discussions suggested unfaithfulness. This husband believed that talking to his wife about condoms was not possible:

You can't tell (your partners) about condoms... where are you going to start? Because we have said (to them) that we have been tested and have been found negative, so if you are found with (condoms) what will she say? (Man, 25-49 years age group).

Although males with more than one partner understood the importance of condom use, these males found it difficult to discuss condom use with either the wife or the girlfriend. This male believed he could not talk about condoms with either partner:

It is not good to discuss (condoms) with the girlfriend...no, it is not possible to talk about (condoms) with the girlfriend (or the wife)... since you sleep with both. (Man, 25-49 years age group).

Female participants had similar concerns about the implications of unfaithfulness if they tried to discuss condom use with a sexual partner. Females believed that they would be perceived as loose if they asked their male partner to use a condom.

\section{Fear of termination of relationship}

Females, younger ones in particular, did not like to discuss condoms with their partners. Young girls feared bringing up the topic about pro- 
tective sexual behaviour with their partners due to concerns about their partners leaving them:

Boys terminate the relationship and get another girl. (Female, 15-24 years age group).

Married women were also afraid to discuss sexual protection with their partners. More specifically, older women did not want to raise the idea of HIV testing as they believed that testing positive led to marriages falling apart:

No, we have never (talked about testing). When you are found positive, the marriage ends there. A lot of families have ended (because of HIV/AIDS). They say if a wife is found positive then the husband is the one who (infected her), and that (the wife was stupid to get infected)... With (this) happening, women start hiding the truth (about their status) and (don't go for testing). (Female, 25-49 years age group).

Talking to a partner about testing for HIV was difficult for males as well. Males were afraid to bring up the idea of couples being tested because they believed that their partners would then assume that they were infected. This male felt trapped about taking protective measures, such as HIV testing, with his long-time partner:

Women (say) that if you want (to get tested) then you are seeing other partners and (women) are suspicious that you are (already) infected...Then an argument begins...Yet you have not gone for (an HIV) test... she takes no time to start the quarrel... she declares that you are infected. (Male, 25-49 years age group).

\section{Fear of rumour and gossip}

At the peer level, participants suggested that they did not talk to their friends about sex regularly, as they were afraid to discuss sexual matters with peers, fearing the discussion would lead to rumour and gossip. Young girls were worried about their reputations in their communities, as illustrated by this young girl's comment when asked if she spoke to her friends about sex:

Not often... Some (friends) start to doubt you... and if I am reckless, I begin to think that ... some (friends) will spread the story... other friends will terminate the friendship. (Female, 15-24 years age group).

Young males did not feel comfortable talking to other young males about sex. They feared they would be ridiculed in public settings and believed it was shameful to discuss sex:

...Boys they do not discuss sex... they feel somehow ashamed. (Male, 15-24 years age group).

Elders also felt uncomfortable talking about sex with other elders. Elders did not acknowledge sexual relationships even if they were aware of their existence:

We do not talk about sex. It is just like stories of witchcraft... I can be talking with my friend here without knowing she has just had sex with somebody... we do not talk about it. (Elder)

Elders felt they could not talk to their grandchildren about sex either. Grandparents perceived that young people did not want to talk to them because they assumed elders would spread rumours about their discussion:

...They get angry when we want to talk with them (about sex)... they get furious, they think that you will take their issues (and) their (HIV) status to the borehole, to church and even at the funeral, (and) people will talk about it. (Elder)

\section{Negative consequences of sex}

Parents and elders who did attempt to discuss sex with their children and grandchildren focused on the negative consequences of engaging in sex. Sexually transmitted infections (STIs), HIV infection and pregnancy were the main negative consequences parents communicated to young people. This mother only warned her daughter about disease:

To my side I can't discuss with my child issues of condoms... but just to tell her that 'if a boy proposes (to have sex with you), refuse because (of) your age... you are still young... (Just) because you can't get preg- nant before you reach puberty (doesn't mean that you can't get) diseases'. (Female, 25-49 years age group).

Besides communicating the negative consequences of sex, adults also focused on the shame their children would bring to the family if they were infected with HIV/AIDS as a result of their sexual behaviour. A male who perceived dying from HIV as shameful to one's family as it indicated promiscuity said:

(I say to young males) 'my boy what you are doing is not good... you are sleeping with girls ... you will end up catching the virus and you will put us in trouble.' (Elder)

Along with AIDS, parents also warned children about pregnancy. Communication about pregnancy was directly related to death: death of the newborn child as well as the parent. A female who believed teenage pregnancy would tear a family apart said:

Some children are in secondary schools and when they come (to talk to me about sex I) tell them that they should not be sleeping with boys because they will get pregnant and get AIDS...And when they deliver a child, that child will die and (they) too will die. (Female, 25-49 yers age group).

Children believed that discussions about sex were negative and that parents consistently depicted sex as dirty and immoral. Parents of young adult females were primarily concerned with pregnancy and young females were lectured about how families and relatives would react to a pregnancy. Young females had many examples about how their parents would react if they found out they were pregnant. Young females said many of their mothers threatened them with extreme action if they became pregnant:

For example my mother said (if) I am pregnant she will hang herself. (Female, 15-24 years age group).

Children feared talking to parents about sex because children believed that parents would jump to the conclusion that their child would become infected with HIV and therefore become a burden to the family:

(Parents tell us that having sex) means that you won't have a bright future... you can get infected at a very young age (and) that means your future won't be bright. (Male, 15-24 years age group).

\section{Discussion}

Given the importance of discussion about safer sex in general and condom use in particular, it is surprising that we know relatively little about factors that promote behaviour that protects against the risks involved. Our quantitative study findings point to the role of efficacy in talking about condom use, perceived benefits of talking about condom use, and injunctive norms as important factors associated with intention to talk about condom use. As shown in Figure 1, people intended to talk about condom use if they perceived that doing so would be beneficial. More importantly, we found an interaction between descriptive norms and perceived benefits: people's intentions to talk about condom use were greatest when they believed that others also did so and that doing so would be beneficial. If talking about condom use was not thought to be beneficial, then descriptive norms were negatively associated with talking intentions: this appears to signify that, for people who do not see much benefit in talking about condom use, belief that others were talking about using condoms resulted in lower intentions to do so oneself.

Findings from our qualitative study suggest that communication between parents and children, partners, and peers was not common. It must be noted that results are based on the perceptions of the participants, meaning that these perceptions may not accurately describe the true nature of communication between various relationships. However, regardless of the reality of the situation, this distinction may 
not be important, as perception is the reality in which each one of us lives. Through the eyes of the participants, when communication took place, messages about sex were mainly about the negative consequences of sexual activity. Many of the study participants believed that they could not talk to their partners or peers about sex due to lack of openness, fear of rumour and gossip, and fear that friendships and/or partnerships would be terminated.

Some parents (fathers in our focus groups) also tended to absolve themselves of any responsibility to talk to their children about sex and sexuality. They expressed the preference that this issue be dealt with by the mass media instead. This suggests that one of the roles that mass media can play is to provide conversation cues and subsequently model discussion. For example, parents may not know how to initiate discussions about sex or they may feel awkward doing so. In this case, mass media programming can handle this issue by adopting a light, humorous approach, by depicting other parents who have initiated dialogue, or by providing conversation starters designed with the parentchild dyad in mind.

Results from both studies imply that there is a need to increase efficacy in talking about sex and protective sexual behaviour, including condom use. For example, both adults and young people in the focus groups made frequent reference to the need for openness. Both groups perceived there were strong barriers to dialogue on sensitive issues, particularly as issues regarding sexual behaviour were traditionally seen to be taboo. In this sense, one can think of self-efficacy and perceived barriers as being at opposite ends of the same continuum: having the confidence to talk about sexual behaviour with our partners has to be understood in the context of the barriers we perceive. Thus, social taboos against open discussion about sexuality could constitute important barriers that Malawians have to overcome in order to feel they can efficiently engage in discussions about sex.

Norms around communicating about sex were also found to influence communication. Many of our participants refrained from discussing sexual issues with their peers because of fears of gossip. Between partners, participants were fearful of discussing condom use and HIV testing because of the implication of unfaithfulness.

Participants brought up many barriers to communication. Interventions should, therefore, attempt to remove barriers to facilitate communication across all relationship types. Both studies suggest that there is a need to convince people that many benefits can be gained from talking and it seems that people intend to talk if they think that they are expected (injunctive norms) to do so. Based upon the study findings, we suggest a number of approaches to increase communication about sex in Malawi.

\section{Providing skills on how to discuss sex}

Regardless of where individuals sought advice, Malawians felt inadequate when discussing sex in general. Study participants who indicated a desire to discuss sex and sexuality complained that they did not know how to have a discussion about sex, suggesting that there is a need to teach individuals how to frame these types of dialogue. In a review of studies on sex communication, ${ }^{37}$ five factors were identified as those needing to be addressed in future behaviour change programming: perceptions of readiness to learn about sex and sexuality; knowledge about sexual practices and norms; having a high level of responsiveness (openness) regarding such topics; the timing of communication; and message content.

\section{Shifting norms about sexual communication}

Findings from this study imply that parents may talk to their children, partners may talk to partners, and peers may talk to peers, but these discussions tend not to be very productive. They may even increase stigma about discussions about sex. Behaviour change pro- grammes could play an integral role in helping Malawians facilitate discussions about sex that increase protective behaviour and encourage, rather than thwart, discussion about sex. Changing entrenched communication patterns is a difficult undertaking, and perhaps more so when the topic is sexuality. Social and cultural norms, which may delineate boundaries surrounding communication about sexuality, need to be addressed to promote and improve communication. Behaviour change interventions could attempt to challenge the traditional norms surrounding discussion about sex and sexuality by framing the new norm as one that encourages and promotes discussion.

\section{Question box method}

Finally, it may be that cultural norms and taboos related to sex discussions are so recalcitrant that bringing about changes would be extremely difficult. The use of a question box may be something to consider as it can provide a safe environment in which answers to residents' questions can be sought. A recent study in rural Malawi used this method by providing a sealed cardboard box with a slit opening that allowed individuals to drop in pieces of paper with their questions on. ${ }^{38}$ Question boxes were placed in seven secondary schools in a western district of Lilongwe and almost 400 questions were collected, including questions on sexual practices, transmission, prevention and condom use. Health educators then provided answers to questions dropped in the question box to each classroom. The study concluded that young people have important unanswered questions regarding HIV transmission and prevention that are the key pieces of information necessary to reduce risk of exposure. Although the question box method may not directly provide information about questions that partners may ask one another, it has the potential to offer a sense of the types of questions Malawians have about sex and sexuality. This method could be used at the community level, as it would allow all individuals within a particular community to ask sensitive and stigmatised questions.

\section{Limitations}

This study has several limitations. The cross-sectional nature of the study design only provides a snapshot of the current situation in relation to communication. It was conducted in districts that have been involved in HIV awareness intervention programmes so results may not be generalised to districts with less exposure to such programmes. There are, however, a number of health-related programmes ongoing all over Malawi so this may not impact external validity to a great extent. In addition, because of the sensitivity of the topic, participants might be more likely to give socially desirable responses, resulting in a social desirability bias. We attempted to limit this bias in the quantitative component by repeatedly telling participants that their responses were confidential. We attempted to limit this bias in the focus groups by not asking individuals about their own behaviour but rather about that of those in their community. Additionally, as far as the qualitative component is concerned, as village leaders nominated participants, study participants may have felt the need to provide socially desirable responses. During the consent process, we repeatedly told participants that their responses would be kept confidential.

Finally, we should note that participants' intentions to talk about sex may not translate into actual discussion. In the current survey, we did not assess participants' actual discussion behaviour, limiting ourselves to only assessing their intentions. This survey was part of our baseline assessment of a longitudinal study, and in subsequent studies we are measuring discussion behaviour in order to assess whether intentions expressed by participants translated into discussion. Nevertheless, expressions of intentions to talk about sexuality comprise an important 
measure of societal openness, and our findings indicate that perceived benefits and self-efficacy are important variables in this regard.

The influence of interpersonal communication on changes in sexual behaviour has been studied for more than 60 years, and interpersonal communication has been used as a component in behaviour change programmes. ${ }^{39}$ Although there are barriers to promoting HIV prevention through interpersonal communication, there are innovative approaches that harness the power of interpersonal communication, and these approaches can be used in behaviour change interventions to promote accurate, influential information that has the potential to increase the adoption of behaviour patterns that protect against HIV infection.

Correspondence: Rupali J. Limaye, Department of Health, Behavior \& Society, 624 N. Broadway, Baltimore, MD 21205, USA.

Tel. +1.410 .6596273 .

E-mail: rlimaye@jhsph.edu

Key words: HIV/AIDS, Malawi, discussion, interpersonal communication, norms, self-efficacy, barriers.

Contributions: all authors contributed equally.

Conflict of interest: the authors declare no conflicts of interest.

Received for publication:12 December 2011.

Accepted for publication: 20 February 2012.

(C) Copyright R.J. Limaye et al., 2012

Licensee PAGEPress, Italy

Journal of Public Health Research 2012; 1:e17

doi:10.4081/jphr.2012.e17

This work is licensed under a Creative Commons Attribution NonCommercial 3.0 License (CC BY-NC 3.0)

\section{References}

1. Office NS, Macro I. Malawi Demographic and Health Survey 2010. Zomba, Malawi and Calverton, Maryland; 2011.

2. UNAIDS. UNAIDS global report on the AIDS epidemic. Geneva, Switzerland: UNAIDS; 2010.

3. Conroy A, Blackie M, Whiteside A, et al. Poverty, AIDS and hunger: breaking the poverty trap in Malawi. Palgrave Macmillan, New York, NY, USA, 2006.

4. Kaler A. My girlfriends could fill a yanu-yanu bus: rural Malawian men's claims about their own serostatus. Demogr Res 2003;11:34972 .

5. Kaler A. AIDS-talk in everyday life: the presence of HIV/AIDS in men's informal conversation in Southern Malawi. Soc Sci Med 2004;59:285-97.

6. Dilorio C, Pluhar E, Belcher L. Parent-child communication about sexuality: a review of the literature from 1980-2002. J HIV/AIDS Prev Educ Adol Child 2003;5:7-32.

7. Namisi FS, Flisher AJ, Overland S, et al. Sociodemographic variations in communication on sexuality and HIV/AIDS with parents, family members and teachers among in-school adolescents: a multi-site study in Tanzania and South Africa. Scand J Public Health 2009;37 Suppl 2:65-74.

8. WHO. Helping parents in developing countries improve adolescents' health. WHO Publ., Geneva, Switzerland, 2007.

9. McBride DC, Freier MC, Hopkins GL, et al. Quality of parent-child relationship and adolescent HIV risk behavior in St. Maarten. AIDS Care 2005;17:S5-S54.
10. Mireku S. Family communication about HIV/AIDS and sexual behavior among senior secondary school students in Accra, Ghana. Afr Health Sci 2003;3:7-14.

11. Halpern-Felsher BL, Kropp RY, Boyer CB, et al. Adolescents' selfefficacy to communicate about sex: its role in condom attitudes, commitment, and use. Adolescence 2004;39:443-56.

12. Aspy CB, Vesely SK, Oman RF, et al. Parental communication and youth sexual behaviour. J Adolesc 2007;30:449-66.

13. DiClemente RJ, Wingood GM, Crosby R, et al. Parent-adolescent communication and sexual risk behaviors among African American adolescent females. J Pediatr 2001;139:407-12.

14. Babalola S, Tambashe B0, Vondrasek C. Parental factors and sexual risk-taking among young people in Cote d'Ivoire. Afr J Reprod Health 2005;9:49-65.

15. Dutra R, Miller KS, Forehand R. The process and content of sexual communication with adolescents in two-parent families: associations with sexual risk-taking behavior. AIDS Behav 1999;3:59-66.

16. Whitaker DJ, Miller KS, May DC, Levin ML. Teenage partners' communication about sexual risk and condom use: importance of parent-teenager communication. Fam Plann Perspec. 1999;31:117-21.

17. Allen M, Emmers-Sommer T, Crowell T. Interpersonal communication research: advances through meta-analysis. In: Allen M, Preiss RW, Gayle B, Burrell N (eds.) Lawrence Erlbaum Associates, Mahwah, NJ, USA, 2002.

18. Noar SM, Carlyle K, Cole C. Why communication is crucial: metaanalysis of the relationship between safer sexual communication and condom use. J Health Commun 2006;11:365-90.

19. Sheeran P, Abraham C, Orbell S. Psychosocial correlates of heterosexual condom use: a meta-analysis. Psychol Bull 1999;125:90-132.

20. Lefkowitz ES, Boone TL, Au TK, Sigman M. No sex or safe sex? Mothers' and adolescents' discussions about sexuality and AIDS/HIV. Health Educ Res 2003;18:341-51.

21. Perrino T, Gonzalez-Soldevilla A, Pantin H, Szapocznik J. The role of families in adolescent HIV prevention: a review. Clin Child Fam Psychol Rev 2000;3:81-96.

22. Bandura A. Social foundations for thought and action: a social cognitive theory. Prentice Hall, Englewood Cliffs, NJ, USA, 1986.

23. Rimal RN, Real K. How behaviors are influenced by perceived norms: A test of the theory of normative social behavior. Commun Res 2005;32:389-414.

24. Bertrand JT, O'Reilly K, Denison J, et al. Systematic review of the effectiveness of mass communication programs to change HIV/AIDS-related behaviors in developing countries. Health Educ Res 2006;21:567-97.

25. Noar SM, Morokoff PJ, Redding C. An examination of transtheoretical predictors of condom use in late-adolescent heterosexual men. J Appl Biobehav Res 2001;6:1-26.

26. Wilson D. Partner reduction and the prevention of HIV/AIDS: The most effective strategies come from within communities. Brit Med J 2004;328:848-9.

27. West J. (Not) talking about sex: youth, identity and sexuality. Sociol Rev 1999;47:525-47.

28. Prazak M. Talking about sex: contemporary construction of sexuality in rural Kenya. Africa Today 2000;47:82-97.

29. Sanders JS, Robinson WL. Talking and not talking about sex: male and female vocabularies. J Commun 1979;29:22-30.

30. Aiken LS, West SG. Multiple regression: testing and interpreting interactions. Sage, Newbury Park, Ca, USA, 1991.

31. Berger C, Calabrese R. Some explorations in initial interaction and beyond: Toward a developmental theory of interpersonal communication. Health Commun Res 1975;1:99-112.

32. Deci EL. Intrinsic Motivation. Plenum, New York, NY, USA, 1975.

33. Clatterbuck GW. Attributional confidence and uncertainty in initial interaction. Human Commun Res 1979;5:147-57. 
34. Bradac J. Theory comparison: uncertainty reduction, problematic integration, uncertainty management, and other curious constructs. J Commun 2001;51:456-76.

35. Creswell J. Research design: qualitative, quantitative, and mixed methods approaches: Sage, Thousand Oaks, CA, USA, 2008.

36. Strauss A, Corbin J. Basics of qualitative reserach: Grounded theory procedures and techniques. Sage, Newbury Park, Ca, USA 1990.
37. Bastien S, Kajula L, Muhwezi W. A review of studies of parent-child communication about sexuality and HIV/AIDS in sub-Saharan Africa. Reprod Health 2011;8:25.

38. Kazembe A. Question box: a tool for gathering information about HIV and AIDS. Afr J Midwifery Womens Health 2010;4:161-5.

39. Valente T, Davis R. Accelerating the diffusion of innovations using opinion leaders. Ann Am Acad Polit S S 1999;566:55-67. 